\title{
Serotonin Increases the Phase Shift of the Circadian Locomotor Activity Rhythm in Mice after Dark Pulses in Constant Light Conditions*
}

\author{
Renata BARTOSZEWICZ and Grażyna BARBACKA-SUROWIAK
}

Accepted April 16, 2007

\begin{abstract}
BARTOSZEWICZ R., BARBACKA-SUROWIAK G. 2007. Serotonin increases the phase shift of the circadian locomotor activity rhythm in mice after dark pulses in constant light conditions. Folia biol. (Kraków) 55: 101-108.

Investigations on the effects of the 5-HT agonists and antagonists on the phase of the circadian locomotor activity rhythm of animals kept in constant light conditions (LL) are rare. Therefore the influence of $\mathrm{R}-(+)-\mathrm{OH}-\mathrm{DPAT}\left(5-\mathrm{HT}_{1 \mathrm{~A}}\right.$ receptors agonist) and metergoline (5- $\mathrm{HT}_{1 / 2 / 7}$ receptors antagonist) on the phase shift of the locomotor-activity rhythm alone and when combined with dark pulses in mice kept in LL are examined. The results indicate that 8-OH-DPAT administered independently at 12.00CT (Circadian Time) shifted the phase of the circadian rhythm and reinforced the effect of dark pulses on this parameter. 12.00CT was defined arbitrarily as the onset of locomotor activity in constant conditions. Metergoline diminished the phase shifts after dark pulses compared to 8-OH-DPAT. The influence of the serotonin agonist showed that serotonin can reinforce the phase shifting effect of the locomotor activity rhythm after dark pulses in LL condition.
\end{abstract}

Key words: 8-OH-DPAT, metergoline, locomotor activity rhythm, dark pulses.

Renata BARTOSZEWICZ, Grażna BARBACKA-SUROWIAK, Institute of Zoology, Department of Neurophysiology and Chronobiology, Jagiellonian University, R. Ingardena 6, 30-060 Kraków, Poland.

E-mail: gsuro@zuk.iz.uj.edu.pl

The suprachiasmatic nuclei (SCN) of the hypothalamus are an integral component of the mammalian circadian system, responsible for generating behavioral and physiological circadian rhythms (SMITH et al. 2001).

Photic information to the SCN is transmitted from the retina via the retino-hypothalamic tract (RHT) and also from the intergeniculate leaflet (IGL) through the geniculo-hypothalamic tract (GHT) (PICKARD et al. 1987; PICKARD \& REA 1997a).

Information from the second type of stimuli, i.e. non-photic stimuli such as arousal and pharmacological substances, reach the SCN through the IGL (ROSENWASSER \& DWYER 2001; GLASS et al. 2003).

The third type of SCN innervation is serotonergic, originating from the mesencephalic median raphe nucleus (MRN) (MEYER-BERNSTEIN \& MORIN 1996; PICKARD et al. 1996; MEYER-BERNSTEIN et al. 1997; MUSCAT et al. 2005). Serotonergic neurotransmission is important in mammalian circadian clock function (JING et al. 2000).
A number of studies have demonstrated that 5-HT afferents convey information about the behavioral state to the SCN circadian clock (ANTLE et al. 2003). Systemic administration of serotonin agonists that increase the intrinsic serotonin level, induce the phase shift of behavioral circadian rhythm (EDGAR et al. 1993; JING et al. 2000). Serotonin inhibits the transmission of light input to the circadian clock during the subjective night (active phase of nocturnal rodents in constant light or dark condition) by action (1) at presynaptic $5-\mathrm{HT}_{1 \mathrm{~B}}$ receptors on retinohypothalamic terminals and (2) at postsynaptic $5-\mathrm{HT}_{1 \mathrm{~A}}$ or $5-\mathrm{HT}_{7}$ receptors on $\mathrm{SCN}$ neurons (REA \& PICKARD 2000; ANTLE et al. 2003). The postsynaptic inhibitory mechanism may play a key role in modulating SCN circadian rhythm by activation of 5-HT receptors and opening the potassium channels (JING et al. 2000).

In mice, BELENKY and PICKARD (2001) described the distribution of 5- $\mathrm{HT}_{1 \mathrm{~B}}$ receptors in presynaptic afferent terminals and postsynaptic SCN processes, and $5-\mathrm{HT}_{7}$ receptors in both pre- and postsynaptic GABA, VIP and VP SCN processes.

* Supported by grant BW/IZ/46/2006. 
These authors suggest that serotonin plays a significant role in the regulation of circadian rhythms by modulating SCN synaptic activity.

Local administration of the serotonin agonist 5carboxamidotryptamine (5-CT), as well as 8-OH-DPAT, into the region of the SCN inhibited light-induced phase advance of the circadian wheel-running rhythm in the hamster (WEBER et al. 1998). It is interesting that 8-OH-DPAT did not attenuate light-induced phase shifts in mice as it did in hamsters (ANTLE et al. 2003).

Serotonergic effects on dark pulse-induced phase shifting of the locomotor-activity rhythm in constant light have not been explored, as also suggested by ROSENWASSER and DWYER (2001).

Therefore, the effects of $\mathrm{R}(+)-8-\mathrm{OH}-\mathrm{DPAT}$ (5- $\mathrm{HT}_{1 \mathrm{~A}}$ agonist) and metergoline (5- $\mathrm{HT}_{1,2,7}$ receptors antagonist) on the phase-shift of the locomotor activity circadian rhythm in mice kept in constant light conditions (LL) were examined. Moreover, the influence of these substances on the phase shifts of the locomotor activity rhythm when administered 30 minutes before dark pulses was ascertained.

\section{Material and Methods}

Fifty four males, 8-week-old, outbred mice (from the Department of Animal Genetics, Jagiellonian University), of a mean body weight of $28 \pm 2 \mathrm{~g}$, were used in the study. The animals were kept in a sound-proof room, in individual metal (wire netting) cages $(13 \times 12 \times 12.5 \mathrm{~cm})$ with free access to a running wheel (diam. $20.5 \mathrm{~cm}$ ), recording the wheel-running activity rhythms in LD 12:12 (light/dark, light from 8.00 to $20.00 \mathrm{hrs}$ local time) and LL (constant light) conditions. Wheel-running activity was continuously recorded by means of an IBM PC/AT computer. The animals were fed a standard diet with water ad libitum. Temperature in the breeding room was $25 \pm 2^{\circ} \mathrm{C}$, humidity $50 \pm 5$ $\%$ and the intensity of the white light in LD and LL was $400 \mathrm{~lx}$ and about $50 \mathrm{~lx}$ inside the cages.

All animals were maintained in LD 12:12 conditions for at least 2 weeks before the start of experiments in LL. The duration of the experiments in LL was four weeks; drugs and dark pulses were applied midway through this period.

The investigation was performed in four groups:

In the first group 16 males were intraperitoneally (i.p.) injected with 8-OH-DPAT [(R)-(+)-8-Hydroxy-DPA Thydrobromide] (Tocris Cookson Ltd), $5 \mathrm{mg} / \mathrm{kg}$ body weight in a saline vehicle (acc.to PICKARD \& REA 1997a: KNOCH et al. 2004) at the beginning of the subjective night $12.00 \mathrm{CT}$ when the animals be- came active. Ten out of 16 animals, 30 minutes after drug injection, were exposed to dark pulses lasting 4 hours. In general the length of the dark pulses applied by various authors were between 1 to 6 hours (SUBBARAJ \& CHANDRASHEKARAN 1981; BOULOS \& RUSAK 1982; BARBACKA-SUROWIAK 2000; BARBACKA-SUROWIAK \& GUT 2001).

In the second group, 18 males were i.p. injected at the same circadian time with metergoline (Sigma-Aldrich), $2 \mathrm{mg} / \mathrm{kg}$ in $0.2 \%$ DMSO (Dimethyl Sulfoxide) vehicle (ANTLE et al.1998; MisTLBERGER \& ANTLE 1998). Ten out of 18 animals were then exposed to 4 hour dark pulses.

In the third group of animals, 10 males (at the beginning of subjective night), were injected i.p. with: $\mathrm{NaCl}$ or DMSO and six out of these were then exposed to dark pulses.

The fourth control group, consisting of 10 animals, was exposed to dark pulses only after being taken out and put again into cages to ascertain whether the application of only the drug had any influence upon the phase of the locomotor activity rhythm.

The magnitude of the phase shifts induced by pharmacological agents alone and/or by dark pulses was calculated by measuring the phase differences between eye-fitted lines, through 7-10 consecutive onsets of the activity time, immediately prior to and after the injections of drugs and/or dark pulses. The magnitude of all phase shifts was referred to circadian hours taking the onset of activity as CT12.00 (CUTRERA et al. 1994).

The mean circadian period (tau) and the amplitude of the circadian wheel-running activity rhythm were calculated for each animal for 5 days prior to and after injection of drugs and dark pulse application by means of auto-correlation and power spectrum analysis to demonstrate the dominant period of the activity rhythm as in the "Chronos processing package" by DOMOSŁAWSKI (1993).

The values of phase shifts were analyzed with the Student's $t$-test for $\mathrm{P}<0.05$ implying statistical significance.

All the figures in the results represent actograms for each individual animal with marked phase shifts after drug application alone or in combination with dark pulse or after dark pulse alone.

\section{Results}

In the constant light condition i.p. injections of 8-OH-DPAT serotonin agonist, at $12.00 \mathrm{CT}$, advanced the phase of the locomotor activity rhythm at a mean value of 114 minutes \pm 8.94 (Fig. 1A). The 4 hour dark pulse applied 30 minutes after 


\section{A}
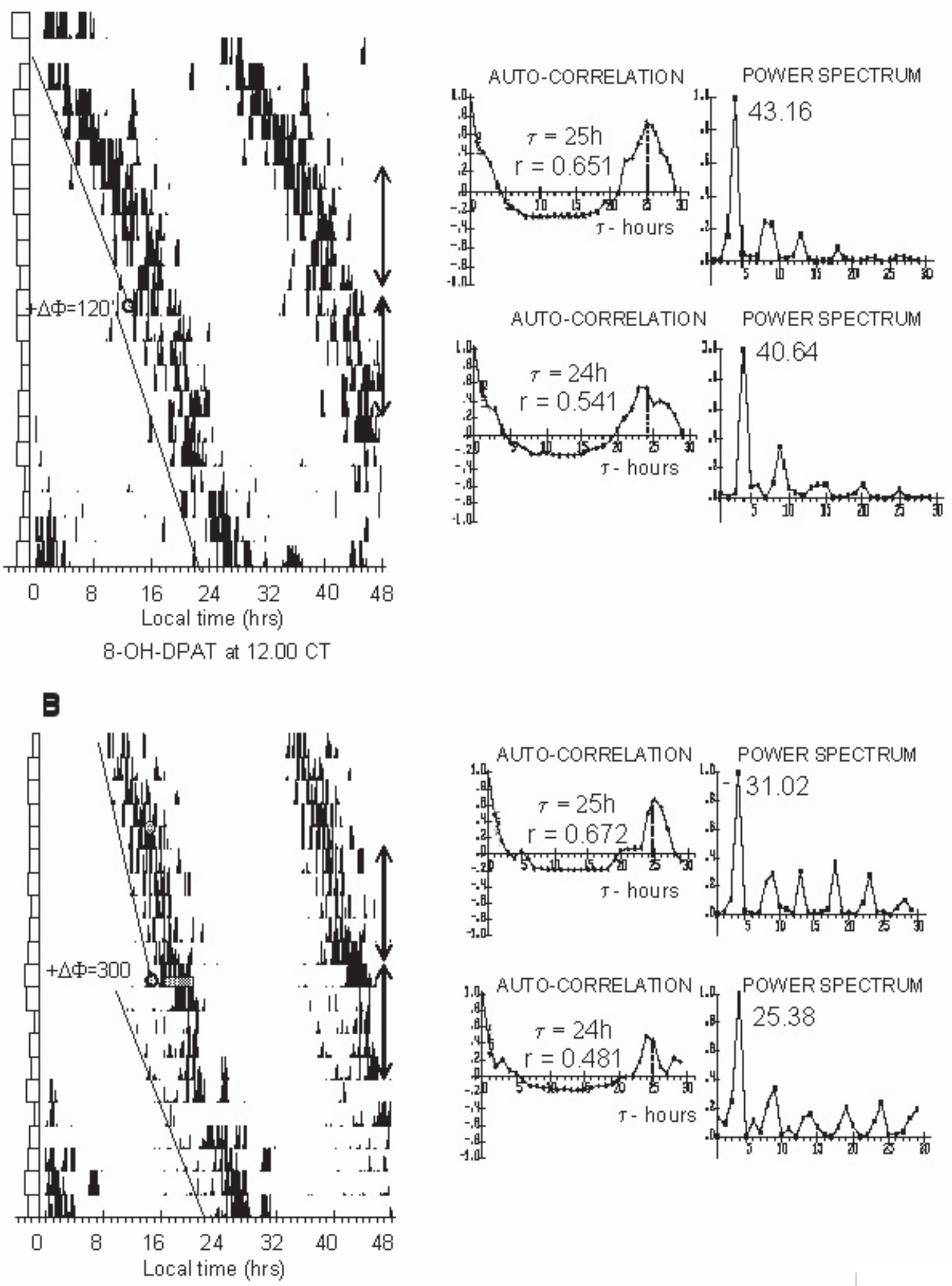

8-OH-DPAT at $12.00 \mathrm{CT}$ and dark pulse

Fig. 1. Representation of a double-plotted actogram of the wheel-running activity rhythm of mice kept in LL condition: A. Phase advance $(+\Delta \Phi)$ of the locomotor activity rhythm after i.p. 8-OH-DPAT injection at 12.00CT (the cyrcle). On the left hand on the Y axis, the rectangles indicate the sum of activity in consecutive days. Two arrows indicate five consecutive days before and after drug injections from which the functions of auto-correlation and power spectrum were calculated. On the right hand of the actogram, the graphs of function of auto-correlation and power spectrum. $\tau-$ represents the period of circadian rhythm. $\mathrm{r}$ - coefficient of auto-correlation. B. Phase advance $(+\Delta \Phi)$ after 8-OH-DPAT injection at 12.00CT and 4-hours lasting dark pulse at $12.30 \mathrm{CT}$ (dim rectangle). On the right hand of the actogram, the graphs of function of auto-correlation and power spectrum for 5 days, before and after drug injection and dark pulse administration. The power spectrum is expressed by the peak indicating percent of activity. 
A

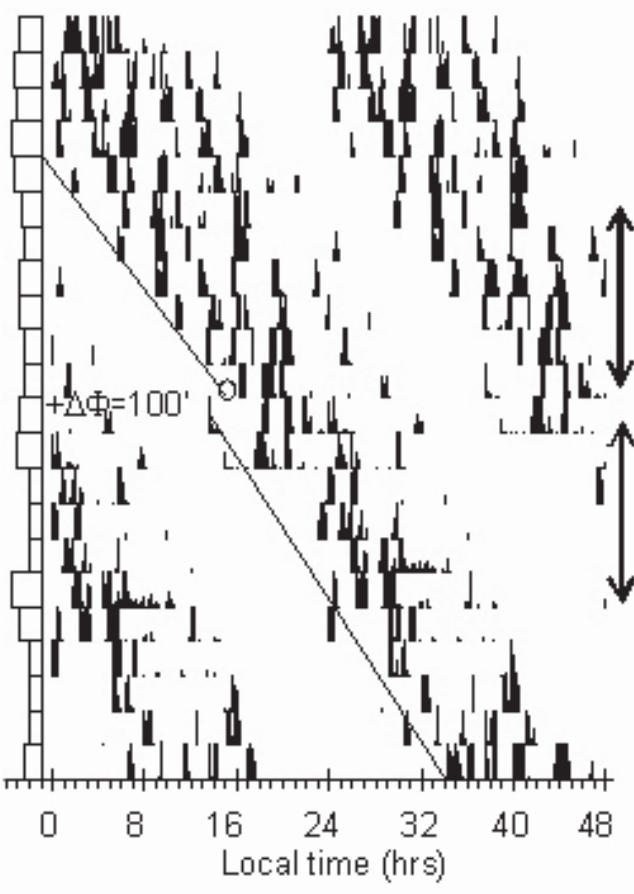

Metergoline at $12.00 \mathrm{CT}$

\section{B}

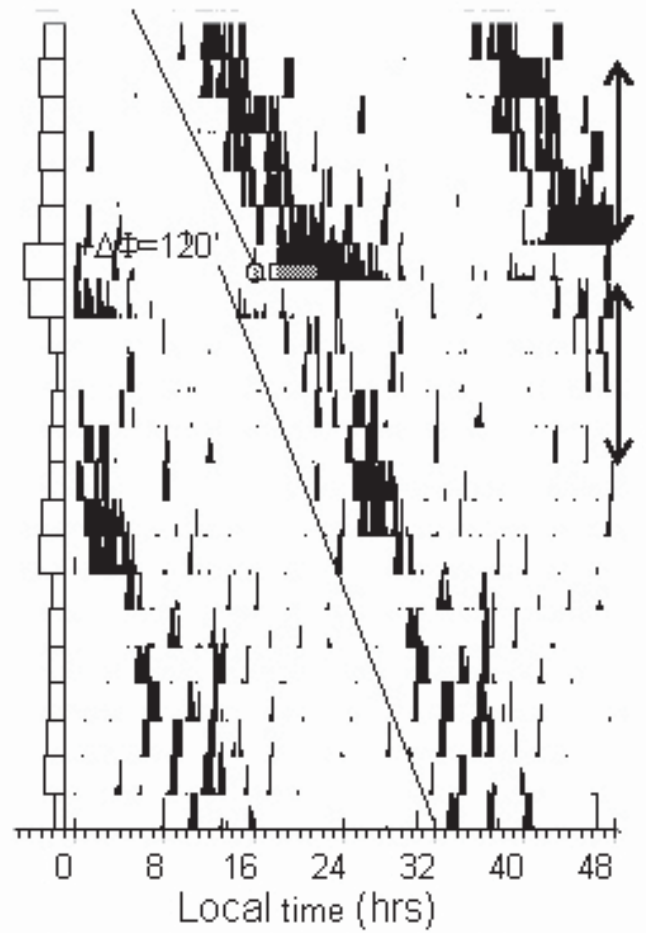

Metergoline at $12.00 \mathrm{CT}$ and dark pulse

\section{AUTO-CORRELATION POWER SPECTRUM}

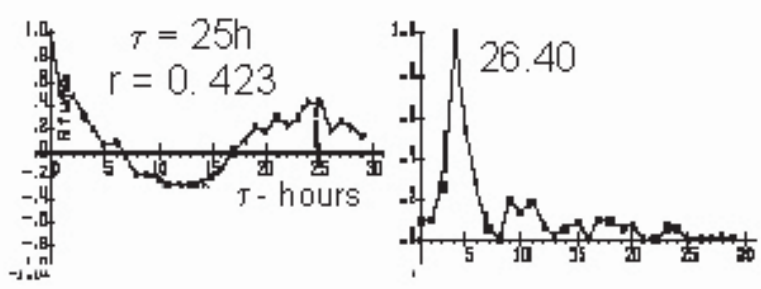

AUTO-CORRELATION POWER SPECTRUM
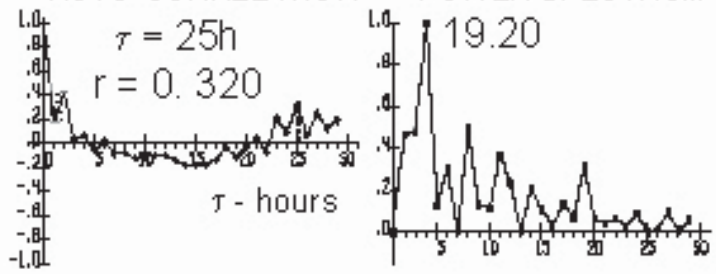
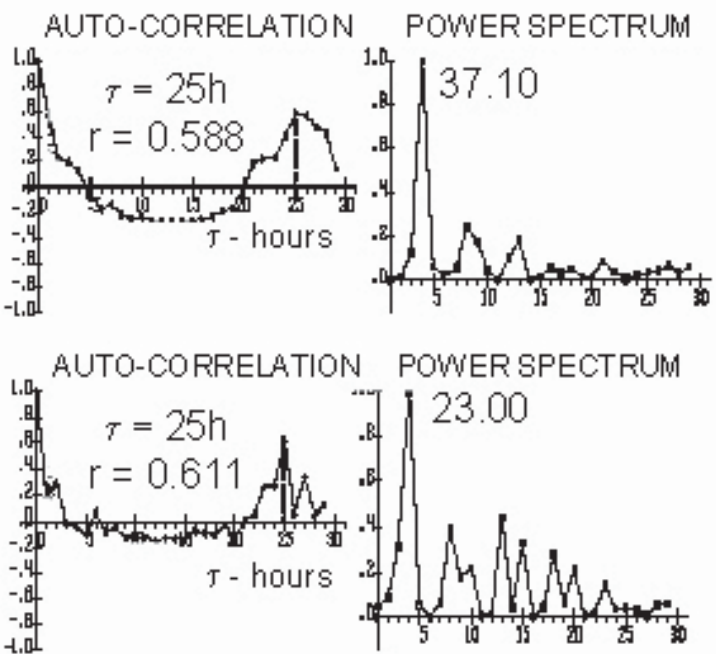

Fig. 2. Representation of a double-plotted actogram of the wheel-running activity rhythm of mice kept in LL conditions: A. phase advance $(+\Delta \Phi)$ of locomotor activity rhythm after i.p. metergoline injection at 12.00CT (the circle). Two arrows indicate five consecutive days before and after drug injection from which the functions of auto-correlation and power spectrum were calculated (right hand actogram). In these graphs the function of auto-correlation and power spectrum are shown. $\tau-$ represents the period of circadian rhythm and $\mathrm{r}-$ coefficient of auto-correlation. B. Phase advance $(+\Delta \Phi)$ after metergoline i.p. injection at 12.00CT and 4-hours lasting dark pulse at $12.30 \mathrm{CT}$ (dim rectangle). On the right hand of the actogram the graphs of function of auto-correlation and power spectrum for 5 days before and after drug injection and dark pulse administration. 

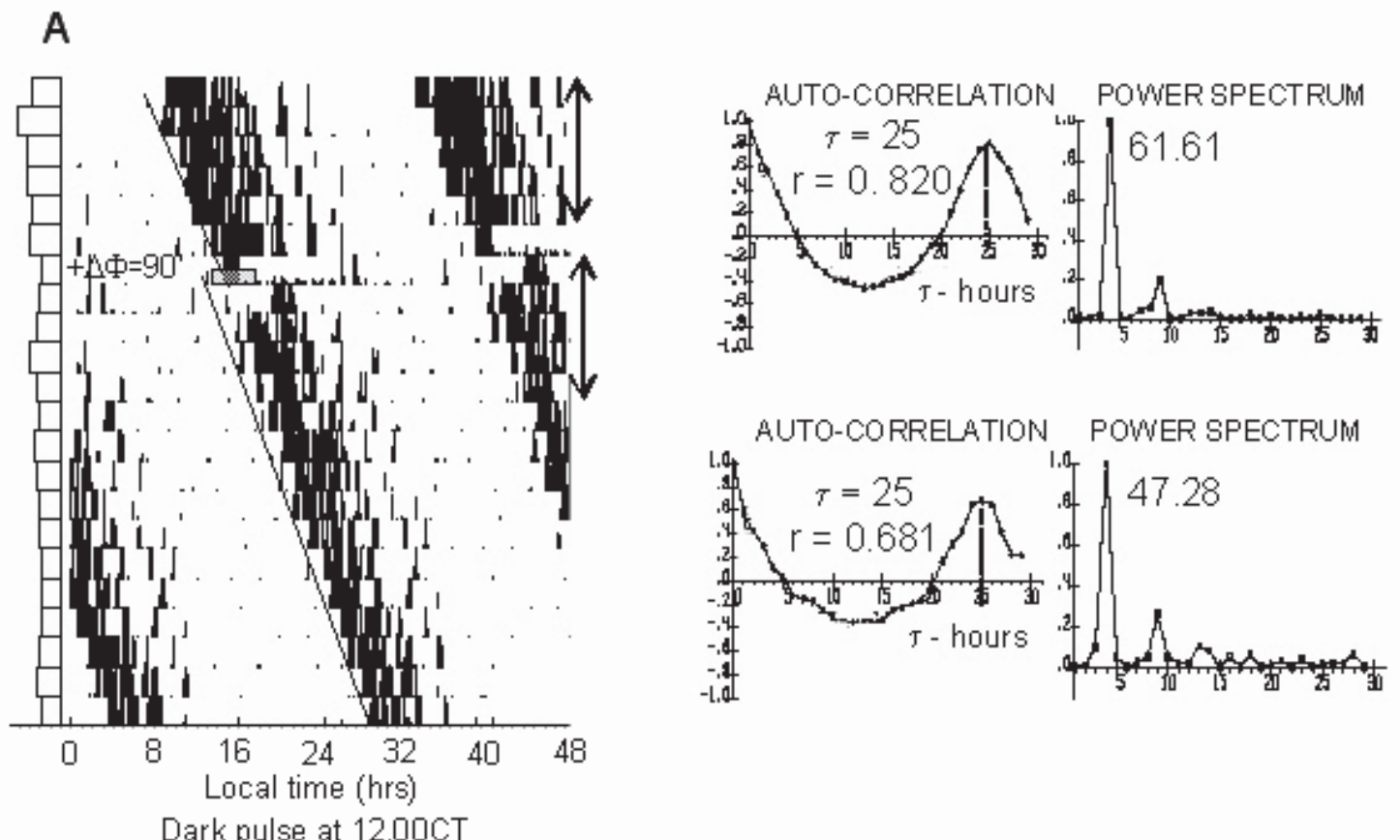

B

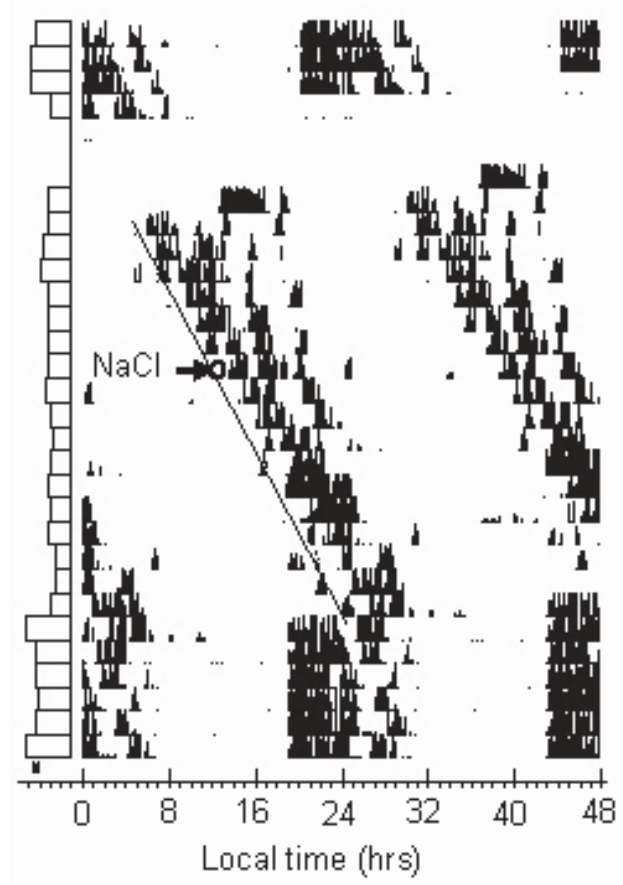

C

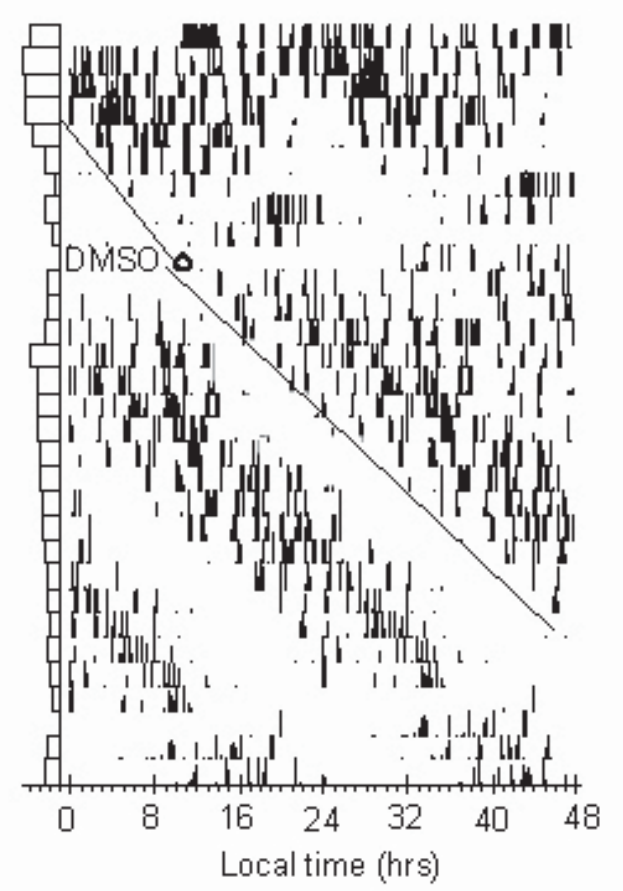

Fig. 3. Representation of a double-plotted actogram of the wheel-running activity rhythm of mice kept in LL conditions: A. phase advance $(+\Delta \Phi)$ of locomotor activity rhythm after dark pulse administered at 12.00 CT (dim rectangle). Two arrows indicate five consecutive days before and after dark pulse administration from which the functions of auto-correlation and power spectrum was calculated. On the right hand of the actogram the graphs of function of auto-correlation and power spectrum for 5 days, before and after dark pulse. $\tau$ - determines period of circadian rhythm and $r$ - coefficient of auto-correlation. B. Representation of double-plotted actogram of wheel-running activity in constant light condition. Arrow and black point indicate time and day of the $\mathrm{NaCl}$ injection. C. Double-plotted actogram of wheel-running activity rhythm. The black point indicates the time and day of the DMSO injection. 


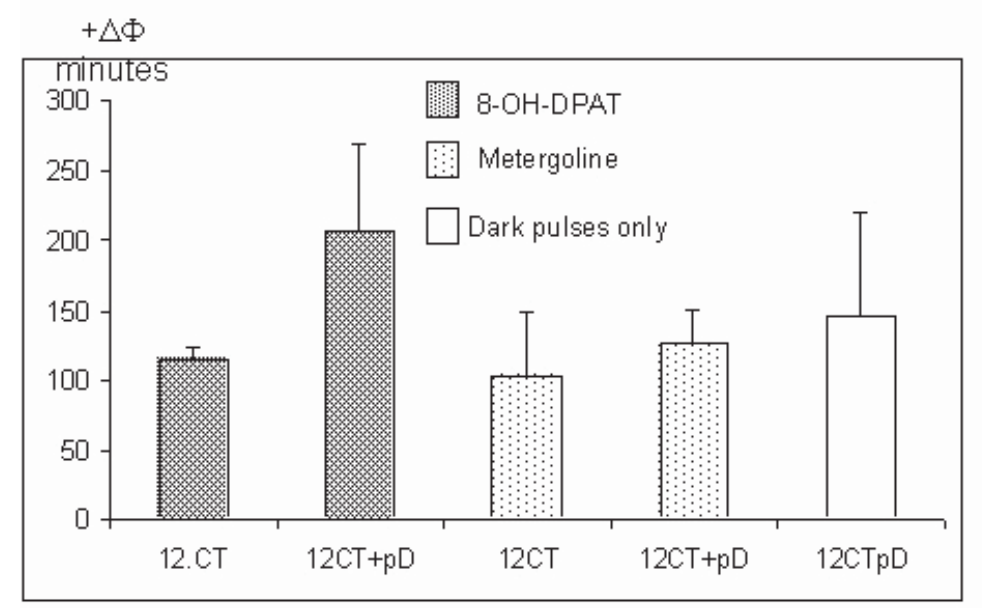

Fig. 4. Diagram of mean advances in minutes of phase shifts of the locomotor activity rhythm after administration (at 12.00CT) of 8-OH-DPAT alone or with dark pulse (+Dp) or metergoline alone or with dark pulse, and after dark pulse only (Dp).

Table 1

Mean value and standard deviation of phase shifts of the locomotor activity rhythm after i.p. drug injection alone, with dark pulses, and dark pulse only

\begin{tabular}{|l|c|c||}
\hline \multicolumn{1}{|c|}{ Agents } & Circadian time of application & $\begin{array}{c}\text { Mean } \Delta \Phi \text {-phase shifts in } \\
\text { minutes }\end{array}$ \\
\hline \hline 8-OH-DPAT & 12.00 & $+114 \pm 8.94$ \\
\hline 8-OH-DPAT and 4hrs lasting dark pulse & 12.00 & $+206 \pm 64.27$ \\
\hline Metergoline & $12.30-16.30$ & $+103.33 \pm 45.09$ \\
\hline Metergoline and 4hrs lasting dark pulse & 12.00 & $+126 \pm 25.10$ \\
\hline Dark pulse only & $12.30-16.30$ & $+145 \pm 74.75$ \\
\hline
\end{tabular}

drug injection (12.30-16.30CT) increased the advances of phases to a mean value of $206.00 \mathrm{~min}-$ utes \pm 64.00 (Fig. 1B). The dark pulses alone advanced the phase of the rhythm to a mean value of $145.00 \pm 74$ minutes (Fig. 3A). Differences in phase shift caused by injection of 8-OH-DPAT combined with dark pulses and by dark pulses alone were statistically significant for $\mathrm{P}<0.05$ (Fig. 4 and Table 1).

Metergoline, a serotonin antagonist, i.p. administered at the same time $12.00 \mathrm{CT}$ induced the phase shifts of the locomotor activity rhythm at a mean value of $103.33 \pm 45.09$ minutes (Fig. 2A) while injected $30 \mathrm{~min}$. before dark pulses shifted the phase of rhythm at a mean value of 126.00 $\pm 25,10$ minutes (Fig. 2B), which, however, is lower than phase shift caused by dark pulse alone.

Figure 4 and Table 1 show mean differences in the influence of the examined drugs upon the phase shifts caused by dark pulses and indicate that only 8-OH-DPAT significantly increased this shift.
After administration of $\mathrm{NaCl}$ (Fig. 3B) or DMSO (Fig. 3C), no phase shifts of the locomotor-activity rhythms were observed. The magnitude of shifts was also non-significant. Furthermore, these vehicles did not change the phase shifts after dark pulses.

Auto-correlation diagrams on the right hand of the actogram showed that the length of the period of the rhythm in LL, after 8-OH-DPAT administration either alone or with dark pulses, shortened it from 25 to 24 hours (Fig. 1A,B). This phenomenon was not observed under the same condition after injection of metergoline (Fig. 2A,B) and after dark pulses alone (Fig. 3A).

\section{Discussion}

Earlier reports have demonstrated that photic responses in the SCN neurons, both in vivo and in vitro, were inhibited by serotonin $5-\mathrm{HT}_{1 \mathrm{~A} / 7}$ receptor 
agonist 8-OH-DPAT, in both hamster (REA et al. 1994) and mice (PICKARD \& REA, 1997b). This inhibitory effect on light-induced phase shift is partially mediated by presynaptic $5-\mathrm{HT}_{1 \mathrm{~B}}$ receptors located on the terminals of the RHT (PICKARD et al. 1996; PICKARD \& REA, 1997b; KOHLER et al. 2000).

There are some species differences between hamster and rat with respect to the in vivo effects of serotonin on the circadian system. During the subjective day, serotonin agonists mimic the phaseresetting action of non photic stimuli in hamsters. In rat, serotonin or its agonists exerted inconsistent effects on the circadian system. During subjective night serotonin agonists block the effect of light in hamster, but induce photic-like phase shifts in rat (KOHLER et al. 2000).

BRADBURY et al. (1997) indicated that 5-HT injected to or near the SCN in mice, reduced photic phase shifts and modulated the magnitude of the photic phase response. ANTLE et al. (2003) observed in wild-type mice that 8-OH-DPAT did not significantly attenuate the light-induced phase shift.

Administration of 8-OH-DPAT in constant darkness at mid-subjective daytime induced a clear and dose-dependant phase advance on the locomotor activity rhythm in mice, whereas no significant phase shifts at other times of subjective day and of subjective night were observed. 8-OH-DPAT also accelerated the re-entrainment of behavioral rhythm to a 6-hr advanced light-dark cycle (HORIKAWA \& SHIBATA 2004).

Experiments on the influence of serotonin upon the locomotor activity of nocturnal rodents kept under LL conditions are very scarce.

The phase response curve of the effect of 8-OH-DPAT on the locomotor activity rhythm in golden hamster kept in LL was constructed by TOMINAGA et al. (1992). They observed the greatest phase advance of activity rhythm after drug injection at $8.00 \mathrm{CT}$, but no significant phase shifts after administration of the drug between CT 12-20.

On the contrary, in our experiment on mice, injections of 8-OH-DPAT at $12.00 \mathrm{CT}$ advanced the phase of the locomotor activity rhythm up to the mean value of two hours (114 min).

In another experiment, exposure of hamsters to two days of LL significantly increased the magnitude of circadian phase shifts induced by nonphotic stimuli, such as the 8-OH-DPAT administered during the day at ZT0, ZT3 and ZT6 (Zeitgeber Zeit 0 was defined arbitrarily as the onset of light phase), and then after injection, the animals were immediately transferred to constant darkness (KNOCH et al. 2004; DUNCAN et al. 2005). The brief constant light treatment markedly enhanced both the amplitude of 8-OH-DPAT induced phase advance and the sensitivity of the animals to the drug, and appears to open the $5-\mathrm{HT}_{1 \mathrm{~A}}$ window to clock (SCN) resetting that is not readily accessible under normal light conditions or in constant darkness (KNOCH et al. 2006; MISTLBERGER 2006).

Our experiments were performed in long constant light during four weeks and the 8-OH-DPAT was applied in the middle of this period. This drug administered at $12.00 \mathrm{CT}$ advanced the phase of locomotor activity at a mean value of 114 minutes, whereas if injected 30 minutes before the dark pulse it caused a phase advance up to $206 \mathrm{~min}$. and this was greater than the phase-shift inducedby 8-OH-DPAT or by dark pulse alone. This indicates that serotonin in long LL potentiated the effect of the dark pulse.

Metergoline, a 5-HT-receptor antagonist, was used in many experiments involving serotonin in the resetting of the SCN circadian clock.

The behavioral attenuation of phase advance to light pulse late in the night was prevented by pretreatment with metergoline. Metergoline also did not significantly attenuate running in the novel wheel (ANTLE et al. 1998; MisTLBERGER \& ANTLE 1998).

The blockade of serotonin receptors by metergoline does not significantly influence the phase shift caused by dark pulse in LL.

In conclusion, our results indicate that serotonin significantly intensified the influence of dark pulses upon the phase shift of locomotor activity rhythm in constant light conditions. These facts confirm results obtained with $8-\mathrm{OH}-\mathrm{DPAT}$. The effect observed is contrary to the influence of 5-HT upon attenuating the phase shift caused by light pulses in constant darkness.

Further experiments are necessary in order to elucidate the action of 8-OH-DPAT at other circadian times in mice.

\section{References}

Antle M. C., Marchant E. G., Niel L., Mistlberger R. E. 1998. Serotonin antagonists do not attenuate activityinduced phase shifts of circadian rhythms in the Syrian hamster. Brain Res. 813: 139-149.

Antle M. C., OGilvie M. D., PiCKARd G. E., Mistlberger R. E. 2003.Response of the mouse circadian system to serotonin 1A/2/7 agonists in vivo: surprisingly little. J. Biol. Rhythms 18: 145-158.

BARBACKA-SUROWIAK G. 2000. Is the PRC for dark pulses in LL a mirror image of the PRC for light pulses in DD in mice? Biol. Rhythm Res. 31: 531-544.

BARBACKA-SUROWIAK G. GUT M. 2001. The effect of dorsal raphe nucleus (DRN) lesions on the locomotor activity rhythm in mice. Folia biol. (Kraków) 49: 77-84. 
BELENKY M. A., PICKARD G. E. 2001. Subcellular distribution of $5-\mathrm{HT}_{1 \mathrm{~B}}$ and $5-\mathrm{HT}_{7}$ receptors in the mouse suprachiasmatic nucleus. J. Comp. Neurol. 432: 371-388.

Bradbury M. J., Dement W. C., Edgar D. M. 1997. Serotonin-containing fibers in the suprachiasmatic hypothalamus attenuate light-induced phase delays in mice. Brain Res.768: 125-134.

Boulos Z., RUSAK B. 1982. Circadian phase response curves for dark pulses in the hamster. J Comp. Physiol. 146: 411-417.

Cutrera R. A., OuArour A., PeVET P. 1994. Effects of 5HT1a receptor agonist 8-OH-DPAT and other non-photic stimuli on the circadian rhythm of wheel-running activity in hamsters under different constant conditions. Neurosci. Lett.172: 27-30.

DOMOSŁAWSKI J. 1993. All-purpose experimental data processing package for Chronobiology. (In: Chronobiology and Chronomedicine, Basic Research and Application. C. Gutenbrunner, G. Hildebrand, R. Moog eds Peter Lang, Frankfurt am Main, Berlin, Bern, N.Y., Paris, Wien): 541-546.

DUNCAN M. J., FrankLIN K. M., DAVIS V. A., GRosSMan G. H., KNOCH M. E., GLASS J. D. 2005. Short-term constant light potentiation of large-magnitude circadian phase shifts induced by 8-OH-DPAT: effects on serotonin receptors and gene expression in the hamster suprachiasmatic nucleus. Eur. J. Neurosci. 22: 2306-2314.

Edgar D. M., Miller J. D., Prosser R. A., DeAn R. R., DEMENT W. C. 1993. Serotonin and the mammalian circadian system: II. Phase-shifting rat behavioral rhythms with serotonergic agonists. J. Biol. Rhythms 8: 17-31.

Glass J. D., Grossman G. H., FARNBAuCH L., DinARdo L. 2003. Midbrain raphe modulation of nonphotic circadian clock resetting and 5-HT release in the mammalian suprachiasmatic nucleus. J. Neurosci. 23: 7451-7460.

HORIKAWA K., SHIBATA S. 2004. Phase-resetting response to (+)8-OH-DPAT, a serotonin IA/7 receptor agonist, in the mouse in vivo. Neurosci. Lett. 368: 130-134.

JiAnG Z-G., TESHIMA K., YANG Y. Q., YOSHIOKA T., AlLEN C. N. 2000. Pre- and postsynaptic actions of serotonin on rat suprachiasmatic nucleus neurons. Brain Res. 866: 247-256.

Knoch M. E., Gobes S. M. H., Pavlovska I., Su C., MisTlBERGER R. E., GLASS J. D. 2004. Short-term exposure to constant light promotes strong circadian phaseresetting responses to nonphotic stimuli in Syrian hamsters. Eur. J. Neurosci. 19: 2779-2790.

KNOCH M. E., SiEGEL D., DunCAN M. J., GLASS J. D. 2006. Serotonergic mediation of constant light-potentiated nonphotic phase shifting of the circadian locomotor activity rhythm in Syrian hamsters. Am. J. Physiol. Regulatory Integrative Comp. Physiol. 291: 180-188.

KoHler M., KalKowsKi A., WollniK F. 2000. Species differences between hamsters and rats with regard to the putative role of serotonin in the circadian system. Biol. Rhythm Res. 31: 340-354.

Meyer-Bernstein E. L., MORIn L. P. 1996. Differential srotonergic innervation of the suprachiasmatic nucleus and the intergeniculate leaflet and ist role in circadian rhythm modulation. J. Neurosci. 16: 2097-2111.

Meyer-Berstein E. L., Blanchard J. H., Morin L. P. 1997. The serotonergic projection from the median raphe nucleus to the suprachiasmatic nucleus modulates activity phase onset, but not other circadian rhythms parameters. Brain Res. 755: 112-120.

MISTLBERGER R. E. 2006. Illuminating serotonergic gateways for strong resetting of the mammalian circadian clock. Am. J. Physiol. Regulatory Integrative Comp. Physiol. 291: 177-179.

Mistlberger R. E., ANTLE M. C. 1998. Behavioral inhibition of light-induced circadian phase resetting is phase and serotonin dependent. Brain Res. 786: 31-38.

MUSCAT L., TISCHLER R. C., MORIN L. P. 2005. Functional analysis of the role of the median raphe as a regulator of hamster circadian system sensitivity to light. Brain Res. 1044: 59-66.

PickARd G. E., Weber E. T., SCOTT P. A., Riberdy A. F., REA M. A. 1996. 5-HT 1 B receptor agonists inhibit lightinduced phase shifts of behavioral circadian rhythms and expression of the immediate-early gene c-fos in the suprachiasmatic nucleus. J. Neurosci. 16: 8208-8220.

PICKARD G. E., RALPH M. R., MENAKER M. 1987. The intergeniculate leaflet partially mediates effects of light on circadian rhythms. J. Biol. Rhythms 2: 35-56.

PICKARD G. E., REA M. A. 1997a. Serotonergic innervation of the hypothalamic suprachiasmatic nucleus and photic regulation of circadian rhythms. Biol. Cell. 89: 513-523.

PICKARD G. E., REA M. A. 1997b. TFMPP, a 5-HT ${ }_{1 \mathrm{~B}}$ receptor agonist, inhibits light-induced phase shifts of the circadian activity rhythm and c-fos expression in the mouse suprachiasmatic nucleus. Neurosci. Lett. 231: 95-98.

ReA M. A., Glass J. D., Colwell C. S. 1994. Serotonin modulates photic responses in the hamster suprachiasmatic nuclei. J. Neurosci. 14: 3635-3642.

REA M. A., PICKARD G. E. 2000. Serotonergic modulation of photic entrainment in the Syrian hamster. Biol. Rhythm Res. 32: 284-314.

Rosenwasser A. M., DWyer S. M. 2001. Circadian phase shifting: relationships between photic and nonphotic phaseresponse curves. Physiol. Behav. 73: 175-183.

SMith B. N., Sollars P. J., Dudek F. E., PiCKARD G. E. 2001. Serotonergic modulation of retinal input to the mouse suprachiasmatic nucleus mediated by $5-\mathrm{HT}_{1 \mathrm{~B}}$ and $5-\mathrm{HT}_{7} \mathrm{re}-$ ceptors. J. Biol. Rhythms 16: 25-38.

SubBaraj R., CHANDRASHEKARAN M. K. 1978. Pulses of darkness shift the phase circadian rhythm in an insectivorous Bat. J. Comp. Physiol. A127: 239-243.

Tominaga K., Shibata S., UeKi S., Watanabe S. 1992. Effects of $5-\mathrm{HT}_{1 \mathrm{~A}}$ receptor agonists on the circadian rhythm of wheel-running activity in hamsters. Eur. J. Pharmacol. 214: 79-84.

WEBER E. T., GANNON R. L., REA M. A. 1998. Local administration of serotonin agonists blocks light-induced phase advances of the circadian activity rhythm in the hamster. J. Biol. Rhythms 13: 209-218. 